\title{
Guía de manejo clínico del paciente con infección por
} SARS-CoV-2

\author{
José L. García-Álvarez* y José L. García-Vigil
}

Universidad Nacional Autónoma de México, Facultad de Medicina, Departamento de Farmacología, Ciudad de México, México

\section{Resumen}

En infección por SARS-CoV-2 (COVID-19), las manifestaciones más comunes son las de vías aéreas superiores; en casos complicados se presenta neumonía intersticial bilateral, insuficiencia respiratoria aguda grave y falla orgánica múltiple que ameritan tratamiento hospitalario y soporte ventilatorio por puntas nasales o mascarilla, así como oxígeno con flujo a presión alta o intubación orotraqueal y ventilación mecánica. No hay antivirales específicos por lo que el manejo es sintomático, así como con antiplaquetarios (ácido acetilsalicílico, dipiridamol), heparina de bajo peso molecular ante hipercoagulabilidad (dímero $D$ aumentado), dexametasona ante indicadores altos de inflamación. Previo consentimiento informado, experimentalmente se emplean antibióticos según los resultados microbiológicos, interferón beta 1b, favipiravir, tocilizumab, ivermectina e inmunoglobulina G. Cuando se presenta gastroenteritis se puede indicar nitazoxanida.

PALABRAS CLAVE: SARS-COV-2. COVID-19. Neumonía. Favipiravir. Tocilizumab. Ivermectina. Inmunoglobulina G. Nitazoxanida.

\section{Guidelines for clinical management of SARS-Cov-2 infection}

\begin{abstract}
In SARS-CoV-2 infection (COVID-19), the most common manifestations involve the upper airways; in complicated cases, bilateral interstitial pneumonia, severe acute respiratory failure and multiple organ failure occur, which require hospital treatment and ventilatory support with nasal cannula or mask and high flow oxygen, or orotracheal intubation and mechanical ventilation. There are no specific antivirals, and thus management is symptomatic, as well as with antiplatelet drugs (acetylsalicylic acid, dipyridamole), low molecular weight heparin when there is hypercoagulability (increased D-dimer), dexamethasone when inflammation indicators are elevated; experimentally, under informed consent, antibiotics are used according to microbiological results, as well as interferon beta 1b, favipiravir, tocilizumab, ivermectin and immunoglobulin $G$. When gastroenteritis occurs, nitazoxanide can be indicated.
\end{abstract}

KEY WORDS: SARS-CoV-2. COVID-19. Pneumonia. Favipiravir. Tocilizumab. Ivermectin. Immunoglobulin G. Nitazoxanide.

\section{Introducción}

En el humano, los virus ARN causan habitualmente enfermedades respiratorias, que oscilan desde resfriado común hasta enfermedad respiratoria severa conocida como síndrome respiratorio agudo severo
(SARS). SARS-CoV-2 es el virus ARN responsable de la pandemia actual, que se originó en Wuhan, China.

Los coronavirus humanos se transmiten por contacto directo con secreciones y a través de gotas de aerosol. Los pacientes infectados también excretan los virus en heces y orina. 
Las partes que conforman la estructura general de los coronavirus son, como en todos los virus animales, la envoltura y la nucleocápside. En la envoltura del coronavirus se encuentra una glucoproteína de membrana (M) de 20 a $35 \mathrm{kDa}$, que forma una matriz en contacto con la nucleocápside. En la envoltura también se encuentra la glucoproteína $\mathrm{S}$, de 180 a $220 \mathrm{kDa}$, que forma las espículas, espigas responsables de la adhesión a la célula huésped. En el caso específico de las espículas de SARS-CoV-2, un dominio de unión para receptores definidos dirigen la adherencia del virus a su receptor celular, la enzima convertidora de angiotensina 2 (Figura 1).

\section{Fisiopatología}

Los pacientes con COVID-19 que se agravan rápidamente presentan datos clínicos y de laboratorio compatibles con el síndrome de activación macrofágica, en cuya fisiopatología se observa lo siguiente:

- Proliferación incontrolada de las células T.

- Activación excesiva de los macrófagos.

- Hipersecreción de citocinas proinflamatorias, interleucinas (IL) $1 \beta$ y 6 , interferón y factor de necrosis tumoral $\alpha$.

En el proceso fisiopatológico se ha encontrado un efecto de unión viral al grupo hemo de la hemoglobina. La unión de la hemoglobina con el coronavirus disminuye la capacidad de transporte de oxígeno, por lo tanto, se genera hipoxia celular con incremento del metabolismo anaeróbico y lesión multiorgánica temprana. ${ }^{2}$ La unión viral parece tener mayor afinidad a la hemoglobina glucosilada, situación que explica por qué el paciente diabético tiene un incremento del riesgo de progresar a enfermedad grave. De los parámetros de laboratorio, la hiperferritinemia constituye el mejor indicador de la respuesta inmune exagerada. ${ }^{3}$

En los pacientes con COVID-19 que se agrava rápidamente se identifica activación patológica de la trombina, observándose múltiples episodios trombóticos que van desde isquemia periférica y tromboembolismo pulmonar hasta coagulación intravascular diseminada. El parámetro de laboratorio más apropiado para reconocer este estado trombofílico es el dímero $\mathrm{D}$ elevado.

\section{Definiciones operativas}

- Caso sospechoso. Persona de cualquier edad que en los últimos siete días haya presentado al menos dos de los siguientes signos y síntomas: fiebre, tos o cefalea, acompañadas de al menos uno de los siguientes signos y síntomas: ${ }^{4}$

- Disnea (dato de gravedad)

- Artralgias

- Mialgias

- Odinofagia/ardor faríngeo

- Rinorrea

- Conjuntivitis

- Dolor torácico

- Caso confirmado. Persona que cumpla con la definición operacional de caso sospechoso y que cuente con diagnóstico confirmado por laboratorio emitido por el Instituto de Diagnóstico y Referencia Epidemiológicos. ${ }^{5}$

\section{Evaluación inicial y consideraciones al ingreso hospitalario}

En la evaluación del paciente con COVID-19 que ingresa al hospital debe prevalecer el juicio clínico. Los pacientes pueden presentar cuadros leves, moderados o graves, incluyendo neumonía, síndrome de distrés respiratorio agudo (SDRA), sepsis y choque séptico. La sospecha de neumonía grave se realizará de forma inmediata durante la valoración inicial si hay presencia de insuficiencia respiratoria (saturación de oxígeno $\left[\mathrm{SaO}_{2}\right]<90 \%$ al aire ambiente), taquipnea e incremento del trabajo respiratorio. Si se trata de una enfermedad no complicada, se podrá valorar la atención domiciliaria con instrucciones claras en cuanto a la identificación temprana de datos de alarma para acudir al hospital a valoración.

\section{Datos clínicos relacionados con infección por SARS-CoV-2}

El periodo de incubación más habitual oscila entre cuatro y seis días, aunque podría llegar a 14 días. Los síntomas son tos en 65 a $80 \%$ de los casos, fiebre al ingreso en $45 \%$ y durante el curso de la enfermedad en $85 \%$, disnea en 20 a $40 \%$, síntomas de infección respiratoria alta en $15 \%$ y síntomas gastrointestinales en $15 \%$. La mayoría de los casos se presenta en adultos, de acuerdo con las series reportadas en China. Los casos pediátricos son escasos, aunque se han descrito en este grupo de edad datos clínicos con predominio de dolor abdominal, diarrea y vasculitis similar a la que se observa en la enfermedad de Kawasaki. 


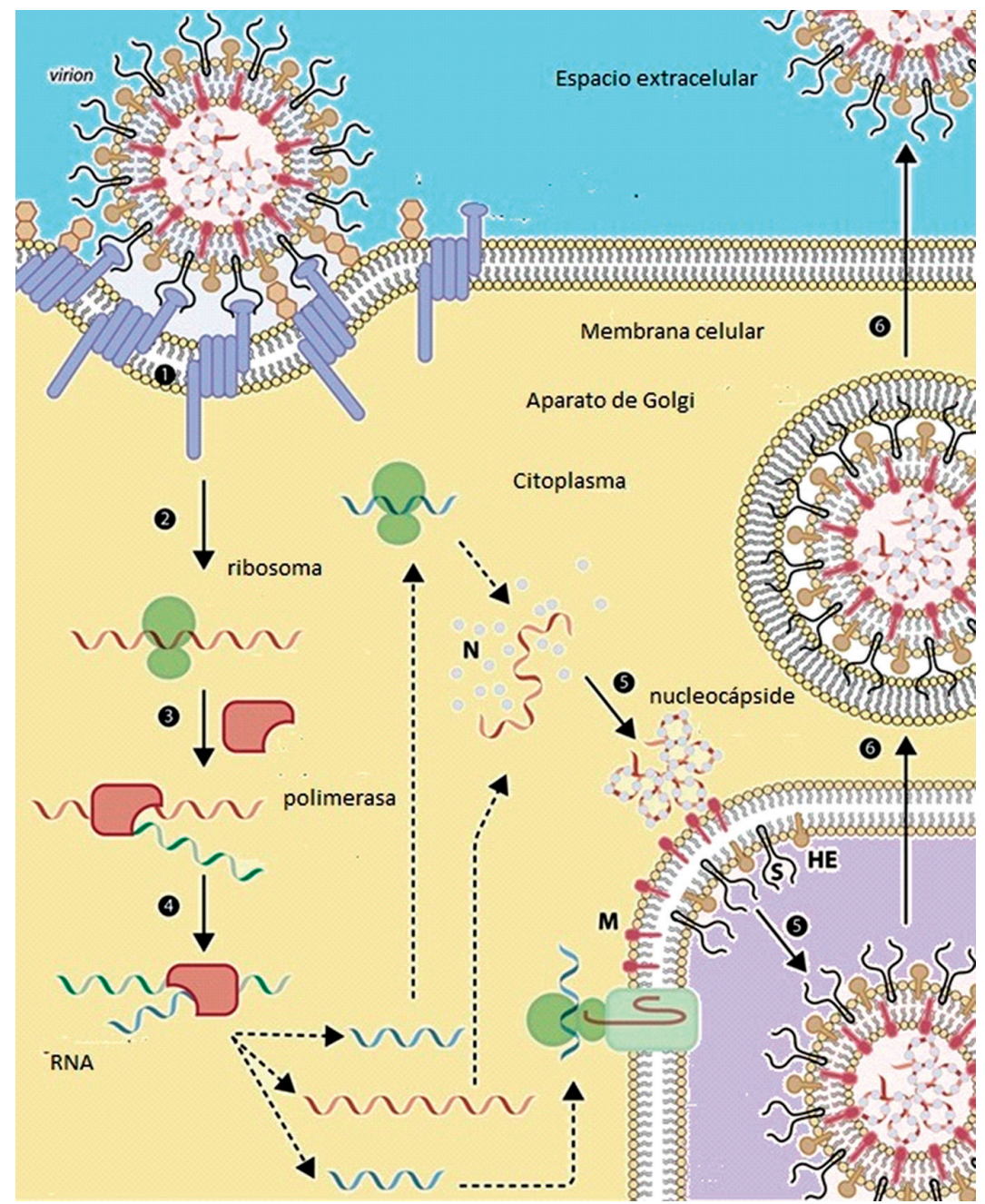

Figura 1. Ciclo de replicación del SARS-CoV- 2.

\section{Estudios de laboratorio y gabinete}

- Biometría hemática con leucopenia y linfopenia en $80 \%$ de los casos.

- Prueba renal, la cual muestra incremento de la relación nitrógeno ureico en sangre/creatinina.

- Parámetros hepáticos con incremento de asparto aminotransferasa, alanino aminotransferasa y bilirrubina total.

- Dímero D positivo, reacción en cadena de la polimerasa (PCR) positiva e incremento de la deshidrogenasa láctica como marcador de lesión tisular.

- Procalcitonina normal, pero con incremento en casos de sobreinfección bacteriana.

- Ferritina e IL-6 altas.

\section{Estudios de imagen}

La radiografía de tórax es normal en los pacientes con enfermedad leve o moderada, pero en algunos casos se observa infiltrado intersticial e imagen en vidrio despulido. En pacientes con COVID-19 severa y neumonía asociada se aprecian infiltrados multisegmentarios bilaterales. En la tomografía de tórax se puede observar de forma más temprana la presencia de los infiltrados bilaterales y la imagen en vidrio despulido.

\section{Diagnóstico microbiológico y pruebas complementarias}

- Prueba rápida de influenza.

- Panel viral respiratorio para descartar virus sincicial respiratorio, adenovirus parainfluenza tipos 1,2 y 3 e influenzavirus tipos A y $B$. 
- Policultivos bacterianos según el caso.

- Reacción en cadena de la polimerasa (PCR) para SARS-CoV-2.

Si se determina que se cumplen los criterios de caso de COVID-19 es necesaria la toma de exudado nasofaríngeo y orofaríngeo.

La determinación sérica de anticuerpos $\lg G$ e $\lg M$ contra COVID-19 son poco útiles en la fase temprana, ya que son positivos después del día $7 .^{6}$

\section{Tratamiento}

No existe actualmente evidencia procedente de ensayos clínicos controlados para recomendar un tratamiento específico en pacientes con sospecha o confirmación de COVID-19, en quienes están indicadas medidas generales, fluidoterapia con cristaloides y control de temperatura con paracetamol en presentación convencional oral o intravenosa, preferentemente. No se recomienda el uso rutinario de antiinflamatorios no esteroideos ${ }^{7}$ ni de corticoides sistémicos, cuyo uso se pueden valorar en casos de síndrome de distrés respiratorio agudo, choque séptico, encefalitis, síndrome hemofagocítico y cuando exista un broncoespasmo franco con sibilancias. Se recomienda la heparina de bajo peso molecular como profilaxis antitrombótica.

\section{Terapia respiratoria}

La oxigenoterapia se inicia ante $\mathrm{SaO}_{2}<92 \%$ al aire ambiente, con el objetivo de mantener los valores por arriba de $90 \%$, preferentemente con dispositivos convencionales a través de cánulas nasales. Los pacientes que ya reciben oxigenoterapia pueden evolucionar a síndrome de distrés respiratorio agudo. Como paso inicial se utilizarán mascarillas con reservorio, procurando mantener flujos mínimos de 10 a $15 \mathrm{~L} /$ minuto y fracción inspirada de oxígeno entre 0.60 y 0.95 .

Las cánulas de oxígeno a alto flujo o la ventilación mecánica no invasiva deben reservarse para pacientes específicos. La ventilación mecánica no invasiva no debe en ningún caso retrasar la indicación de intubación. Puede suministrarse hasta $70 \mathrm{~L} /$ minuto de oxígeno a alto flujo, medida que comparada con la oxigenoterapia convencional disminuye la necesidad de intubación; no se recomienda en pacientes con hipercapnia, inestabilidad hemodinámica o falla multiorgánica.

De ser necesaria ventilación mecánica invasiva, la intubación será realizada por personal experto, con las medidas de precaución para evitar la transmisión aérea del virus.

El tratamiento con fármacos en micronebulizaciones no se recomienda por la posibilidad de generar aerosoles que incrementen el potencial de transmisión viral. En caso de espasmo bronquial se recomienda el uso de dispositivos individuales presurizados en conjunto con una cámara espaciadora.

Los antibióticos no están recomendados de entrada, aunque podrían estar indicados en función de la clínica, los resultados analíticos de sangre o los resultados microbiológicos. ${ }^{8}$

El oseltamivir es un fármaco inhibidor de neuroaminidasa que se utiliza en casos positivos de influenza y en los pacientes con síndrome respiratorio agudo sin etiología precisa o sin resultados específicos.

\section{Tratamiento antiviral específico}

Hasta el momento no hay tratamiento antiviral específico, por lo cual se debe considerar el uso de los siguientes previo consentimiento informado del paciente:

- Hidroxicloroquina. Fármaco antipalúdico en comprimidos de $200 \mathrm{mg}$, con uso difundido en enfermedades reumatológicas. Su efecto antiviral se atribuye a estabilización de los lisosomas del macrófago, activación y alcalinización de los fagolisosomas, inhibición de la replicación viral y supresión de la liberación de IL-6 y del factor de necrosis tumoral. La dosis inicial es de $400 \mathrm{mg}$ cada 12 horas el primer día y después $400 \mathrm{mg}$ diarios durante siete días en casos leves y moderados, con extensión a 14 días en los pacientes con neumonía grave.

- Cloroquina. Fármaco que se obtiene en comprimidos de $150 \mathrm{mg}$. La dosis es de $300 \mathrm{mg}$ cada 12 horas el primer día y posteriormente $300 \mathrm{mg}$ cada 24 horas. Como efectos secundarios se han registrado maculopatía y alargamiento del segmento QT en el electrocardiograma. Aunque se desconoce la eficacia de este medicamento en COVID-19, en diversas series de casos en China y Europa se demostró negativización de la viremia a los siete días.

En series recientes no se han registrado beneficios con el uso de hidroxicloroquina y cloroquina, incluso se ha observado incremento de la mortalidad por arritmias cardiacas, por lo que se requieren estudios completos, de fase I a III, para determinar la eficacia y seguridad farmacológica. 
- Lopinavir/ritonavir. Inhibidor de la proteasa disponible en tabletas de 200/50 mg. Posología: dos tabletas cada 12 horas durante siete a 10 días, que en pacientes con enfermedad moderada o con neumonía grave puede prolongarse hasta 14 días. Como efectos adversos frecuentes se ha registrado diarrea, náuseas, vómito, hipertrigliceridemia e hipercolesterolemia; y como infrecuentes, pancreatitis y prolongación del segmento QT en el electrocardiograma. La eficacia de este fármaco no fue demostrada en una serie de casos publicada en 2020 en el New England Journal of Medicine. ${ }^{9,10}$

- Remdesivir. Inhibidor del ARN-polimerasa viral que reduce la replicación viral. La dosis de carga sugerida el primer día es de $200 \mathrm{mg}$ en forma intravenosa, con dosis de mantenimiento de $100 \mathrm{mg}$ vía intravenosa/día durante los días 2 a 10. La hipotensión infusional constituye el principal efecto adverso e indicación de precaución. Se observó eficacia moderada de este fármaco en un ensayo aprobado en abril de 2020 por la Food and Drugs Administration de Estados Unidos para uso emergente en COVID-19.11

- Interferón beta-1b. Inhibidor de un amplio espectro de genes que limitan la síntesis de la proteína quinasa-R activada por ARN y de 2'-5' oligoadenilato sintetasa; activa la proteína MxA y limita la replicación viral. La dosis indicada en neumonía grave es $0.25 \mathrm{mg}$ por vía subcutánea cada 48 horas durante 10 a 14 días. Los principales efectos adversos e indicaciones de precaución son fiebre, cefalea, hipertonía, miastenia, rash, náusea, diarrea, linfopenia, leucopenia, reacción local, debilidad, artralgias y síndrome pseudogripal. Se desconoce la eficacia de este fármaco en el tratamiento de COVID-19.

- Favipiravir. Inhibidor del ARN viral dependiente de la ARN polimerasa que provoca la terminación de la cadena peptídica y previene la elongación del ARN viral. Previene la formación de proteínas virales que favorecen el ataque al grupo hemo de la hemoglobina. La dosis recomendada es de 2400 a $3000 \mathrm{mg}$ cada 12 horas el primer día, seguida de 1200-1800 mg cada 12 horas. Favipiravir está disponible solo en Japón y su distribución no es viable hasta el momento en América y Europa.

- Tocilizumab. Anticuerpo monoclonal inhibidor de la acción de IL-6 que se emplea para el tratamiento del síndrome de liberación de citocinas.
En series pequeñas de 21 pacientes se observó mejoría en $91 \%$ de los casos con la administración de $400 \mathrm{mg}^{12,13}$

De ser necesaria terapia antiviral específica y tratamiento antimicrobiano coadyuvante, se debe tener precaución de no combinar cloroquina y lopinavir/ ritonavir con macrólidos o quinolonas, por el riesgo de alargamiento del segmento QT en el electrocardiograma. Será conveniente considerar el uso de betalactámicos y en los pacientes alérgicos a penicilinas, de carbapenemas (Tabla 1).

\section{Propuestas de tratamiento}

Con la comprensión de los procesos fisiopatológicos implicados en COVID-19 es posible proponer tratamientos farmacológicos con la finalidad de bloquear aspectos estratégicos.

Se plantea el uso de cloroquina e hidroxicloroquina, ya que estos medicamentos promueven la modificación del pH celular y disminuyen la posibilidad del proceso de endocitosis viral y la unión de las proteínas virales al grupo hemo y, por tanto, aminoran la liberación de hierro y la posibilidad de hipoxia celular; además, sus efectos de inmunomodulación reducen la posibilidad de progresión a síndrome de liberación de citocinas.

También podrían emplearse fármacos inmunomoduladores, como la colchicina y pirfenidona, con el objetivo de reducir el riesgo de desarrollo de síndrome de liberación de citocinas y, de forma secundaria, la posibilidad de progresión a fibrosis pulmonar en los pacientes con neumonía ya establecida.

Los corticosteroides deben utilizarse en forma racional, ya que disminuyen la depuración viral al inhibir el adecuado proceso inmunológico. En ciclos cortos de cinco a 10 días, los corticosteroides pueden favorecer la recuperación, especialmente cuando se ha logrado controlar la replicación viral, comprobada mediante la reducción progresiva de la proteína $C$ reactiva ultrasensible, la cual por lo general se observa después del día 5 de iniciado el tratamiento antiviral específico. Se recomienda 0.5 a $1 \mathrm{mg} \mathrm{kg} / \mathrm{día}$ de metilprednisolona o $6 \mathrm{mg} / \mathrm{dí}$ de dexametasona o sus equivalentes de prednisona y deflazacort.

Pueden emplearse fármacos que reduzcan la respuesta inmunológica exagerada a través del bloqueo de la vía Jak/Stat (baricitinib o ruxolitinib), vía intracelular implicada directamente en la transducción de información generada por diversas citocinas y que controla respuestas inmunitarias e inflamatorias 
Tabla 1. Criterios para diagnóstico y recomendaciones de tratamiento

\begin{tabular}{|c|c|}
\hline Escenario clínico & Recomendación \\
\hline $\begin{array}{l}\text { Neumonía grave en paciente sospechoso o confirmado con } \\
\text { COVID-19. Incluye neumonía más cualquiera de los siguientes. } \\
\text { - Frecuencia respiratoria > 30/minutos } \\
\text { - Saturación de oxígeno < } 90 \text { \% con fracción inspirada de } \\
\text { oxígeno a } 21 \text { \% } \\
\text { - Requerimiento de ventilación mecánica asistida. } \\
\text { - Deterioro del estado de alerta } \\
\text { - Inestabilidad hemodinámica y requerimiento de aminas } \\
\text { vasoactivas } \\
\text { - Puntuación en CURB-65 (escala de predicción de mortalidad } \\
\text { en pacientes con neumonía adquirida en la comunidad) > } 2 \\
\text { puntos } \\
\text { - Incremento de infiltrados pulmonares en más de } 50 \text { \% entre } \\
24 \text { y } 48 \text { horas. } \\
\text { - Requerimiento de estancia en la unidad de cuidados } \\
\text { especiales }\end{array}$ & $\begin{array}{l}\text { 1. Tratamiento de sostén } \\
\text { 2. Ivermectina } \\
\text { 3. Hidroxicloroquina o cloroquina } 400 \mathrm{mg} \text { o } 300 \mathrm{mg} \mathrm{c} / 12 \text { hora el } \\
\text { primer día y continuar } 400 \mathrm{mg} \text { o } 300 \mathrm{c} / 24 \text { horas durante siete días, } \\
\text { considerando extender a } 10-14 \text { días } \\
\text { 4. Lopinavir/ritonavir } 200 / 50 \mathrm{mg} \text {. Dos tabletas } \mathrm{c} / 12 \text { horas durante siete } \\
\text { a } 10 \text { días } \\
\text { 5. Remdesivir } 200 \mathrm{mg} \text { dosis inicial y continuar } 100 \mathrm{mg} \text { vía intravenosa } \\
\text { c/24 horas por } 10 \text { días, considerando extender plazo a } 14 \text { días en } \\
\text { caso necesario } \\
\text { 6. Tratamiento antimicrobiano habitual para neumonía y según } \\
\text { resultados de cultivos } \\
\text { 7. Heparina de bajo peso molecular. Enoxaparina } 1 \mathrm{mg} / \mathrm{kg} \mathrm{c} / 12 \text { horas } \\
\text { 8. Corticosteroides. Metilprednisolona o dexametasona, ciclo corto, } \\
\text { máximo } 10 \text { días } \\
\text { 9. Tocilizumab } 8 \mathrm{mg} / \mathrm{kg}\end{array}$ \\
\hline $\begin{array}{l}\text { Neumonía sin criterios de gravedad en paciente sospechoso } \\
\text { o confirmado de COVID-19 y con alguna de las siguientes } \\
\text { condiciones. } \\
\text { - Edad > } 60 \text { años } \\
\text { - Diabetes mellitus } \\
\text { - Enfermedad cardiovascular } \\
\text { - Enfermedad pulmonar obstructiva crónica } \\
\text { - Enfermedad renal crónica. } \\
\text { - Patologías estructurales en pulmón } \\
\text { - Inmunocompromiso } \\
\text { Buscar intencionadamente datos de respuesta inmunotrombótica }\end{array}$ & $\begin{array}{l}\text { 1. Tratamiento de sostén } \\
\text { 2. Ivermectina } \\
\text { 3. Hidroxicloroquina o cloroquina } 400 \mathrm{mg} \text { o } 300 \mathrm{mg} \text { c/12 horas el } \\
\text { primer día y continuar } 400 \mathrm{mg} \text { o } 300 \mathrm{mg} \text { cada } 24 \text { horas por siete días } \\
\text { considerando extensión a } 10 \text { días } \\
\text { 4. Lopinavir-ritonavir } 200 / 50 \mathrm{mg} \text {. } 2 \text { tabletas c/12 horas durante siete a } \\
10 \text { días } \\
\text { 5. Heparina de bajo peso molecular } \\
\text { Enoxaparina } 1 \mathrm{mg} / \mathrm{kg} \mathrm{c} / 12 \text { horas } \\
\text { 6. Tratamiento antimicrobiano habitual para neumonía } \\
\text { 7. Corticosteroides. Metilprednisolona o dexametasona ciclo corto, } \\
\text { máximo } 10 \text { días }\end{array}$ \\
\hline Neumonía sin criterios de gravedad y sin comorbilidades & $\begin{array}{l}\text { 1. Tratamiento sintomático (paracetamol) } \\
\text { 2. Tratamiento antimicrobiano habitual para neumonía } \\
\text { 3. Ivermectina }\end{array}$ \\
\hline $\begin{array}{l}\text { Formas leves con comorbilidades } \\
\text { Con radiografía de tórax normal }\end{array}$ & $\begin{array}{l}\text { 1. Tratamiento sintomático (paracetamol) } \\
\text { 2. Tratamiento antimicrobiano habitual (levofloxacino, azitromicina o } \\
\text { claritromicina) } \\
\text { 3. Ivermectina }\end{array}$ \\
\hline Formas leves sin comorbilidades y radiografía de tórax normal & $\begin{array}{l}\text { 1. Tratamiento sintomático (paracetamol) } \\
\text { 2. Considerar tratamiento antimicrobiano habitual (amoxicilina } \\
\text { clavulanato) en caso de datos de infección bacteriana } \\
\text { 3. Ivermectina }\end{array}$ \\
\hline
\end{tabular}

Existen diversos agentes farmacológicos en proceso de estudio como nitaxozanida, agente diseñado para el tratamiento de infecciones gastrointestinales predominantemente parasitarias, con el cual se ha observado actividad in vitro contra SARS-CoV-2 y MERS-CoV al inhibir su proliferación y poseer capacidad inmunomoduladora. Se requieren estudios prospectivos para evaluar la eficacia de nitaxozanida en la práctica clínica, ya que es un fármaco con alta disponibilidad.
El mesilato de camostat es un fármaco aprobado en Japón para el tratamiento de la pancreatitis. In vitro previene la incorporación intracelular de SARS-CoV-2 al inhibir la serina proteasa; en un futuro promete ser un fármaco adecuado para el tratamiento de la infección por COVID-19.

Respecto al tratamiento con inmunoglobulina, al igual que en protocolos contra la influenza A (H1N1) en 2009, en series anecdóticas se observó respuesta adecuada con la administración de plasma de 


\section{Líneas de ataque en COVI-19}

Estrategias de tratamiento farmacológico en diferentes punto del ciclo de la replicación de SARS-CoV-2

1a. Fusión

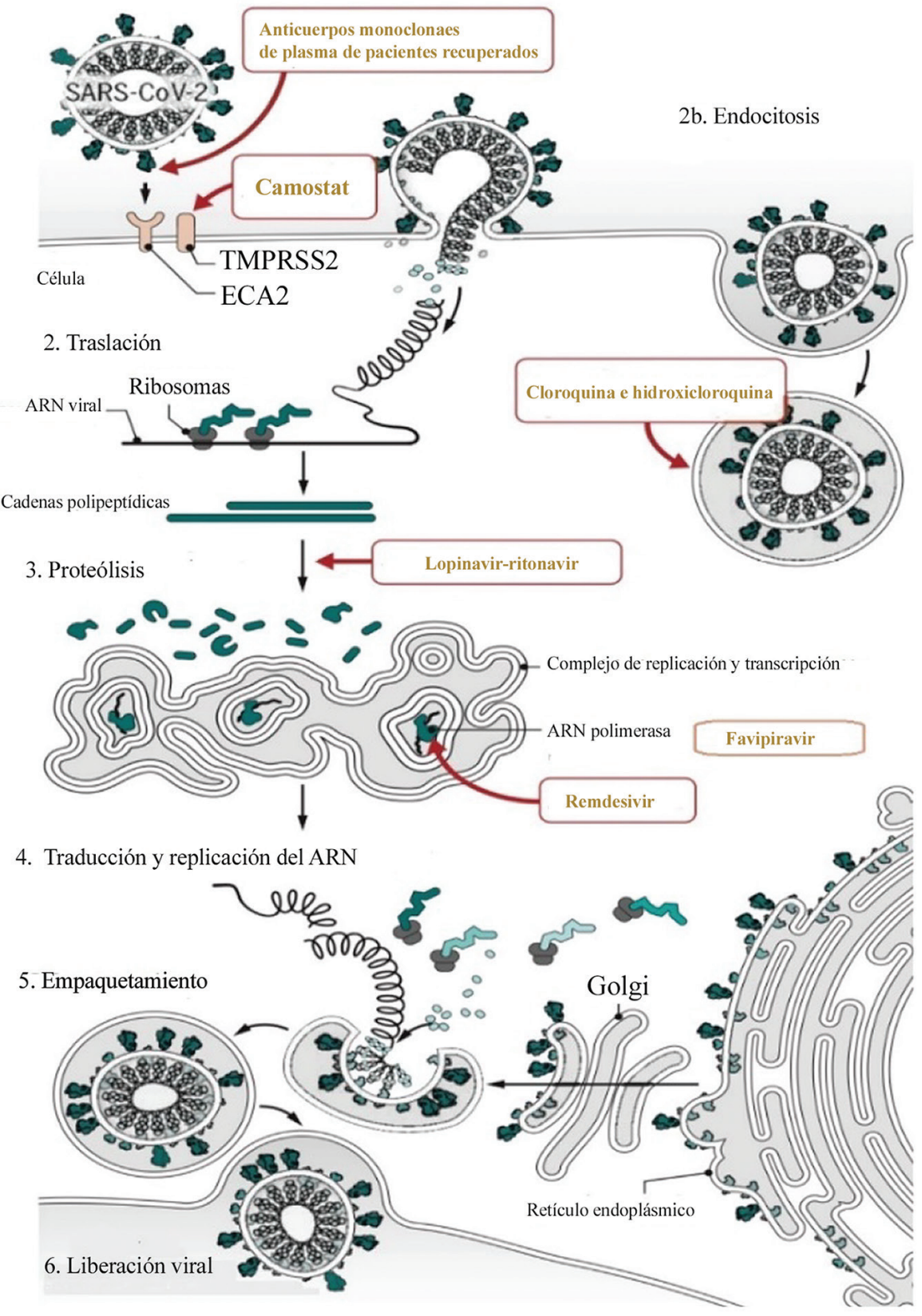

Figura 2. Etiopatogenia de COVID-19.

pacientes recuperados de SARS y MERS. Se recomienda su administración en los primeros siete a 10 días del inicio de la enfermedad, ya que en ese momento la replicación viral está en su punto máximo y la respuesta inmune del huésped no se ha desarrollado en ese momento.
La ivermectina es un antiparasitario autorizado por la Food and Drugs Administration con el cual se ha demostrado actividad antiviral in vitro contra una amplia gama de virus. El mecanismo de acción radica en inhibir la importación nuclear de proteínas virales al huésped. La ivermectina es activa contra virus ARN al 
inhibir la interacción de una proteína denominada IMP a/B1.

En estudios recientes in vitro se utilizó ivermectina en cultivos de células infectadas con SARS-CoV-2; se determinó la presencia de ARN viral mediante PCR con transcriptasa inversa (RT-PCR). Se demostró la reducción de la carga viral a las 48 horas de la administración del fármaco, con reducción de $93 \%$ del ARN de SARS-CoV-2 en el sobrenadante del cultivo y de $98 \%$ en el ARN viral asociado a las células. La reducción fue de aproximadamente 5000 veces el ARN viral en la muestra tratada con ivermectina en comparación con la muestra control, lo que indica que el tratamiento con ivermectina resultó en la pérdida eficaz del material viral a las 48 horas. De tal forma, puede implementarse el tratamiento con ivermectina como actualmente está aprobado. ${ }^{14,15}$ Se propone el siguiente régimen con ivermectina (presentación en tabletas de $6 \mathrm{mg}$ ) dependiendo del peso del paciente y la gravedad de la enfermedad: $15-20 \mathrm{~kg}, 3 \mathrm{mg} ; 21-40 \mathrm{~kg}, 6 \mathrm{mg} ; 41-60 \mathrm{~kg}$, $9 \mathrm{mg} ; 61-80 \mathrm{~kg}, 12 \mathrm{mg} ; 81-100 \mathrm{~kg}, 15 \mathrm{mg} ; 101-120 \mathrm{~kg}$, $18 \mathrm{mg}$; en casos leves a moderados durante tres días y en graves durante seis días.

Los efectos secundarios de la ivermectina son escasos, como dolor abdominal, anorexia, diarrea y náusea, pero se requiere administrar con precaución en pacientes que reciben tratamiento con psicotrópicos gabaérgicos y macrólidos.

En series anecdóticas se refiere el uso a dosis convencionales de antirretrovirales como tenofovir y emtricitabina (que se emplean contra el virus de la inmunodeficiencia humana) para sustituir a lopinavir/ ritonavir; los resultados han sido prometedores, por lo que en un futuro se debe ponderar la disponibilidad, eficacia y tolerabilidad de ivermectina.

Si bien se han probado con mayor o menor éxito las propuesta anteriores, se reconoce que la estrategia más efectiva a largo plazo es el desarrollo de vacunas que otorguen vacunas que otorguen inmunidad. ${ }^{16,17} \mathrm{La}$ profilaxis en el personal de salud y contactos no está aprobada, aunque se debe ponderar en un futuro por disponibilidad, eficacia y tolerabilidad el uso de ivermectina.

\section{Alta del paciente}

Los casos en investigación en los que se descarte COVID-19 se guiarán por los criterios clínicos habituales. En los casos probables o confirmados de COVID-19, además del criterio clínico para el alta médica, será necesario demostrar la negativización de las muestras del tracto respiratorio para finalizar el aislamiento. Para ello será necesario obtener dos resultados negativos de PCR en dos muestras respiratorias adquiridas con una separación mínima de 24 horas entre ellas y después de que el paciente ya no presente síntomas. Una vez obtenidos los resultados, se procederá al alta ${ }^{18,19}$ (Figura 2).

Asimismo, no se ha establecido la prioridad con la que se debe atender a los pacientes graves por grupos de edad, pero se considera importante que prevalezca la experiencia del médico tratante y los lineamientos de la Guía Bioética para Asignación de Recursos Limitados de Medicina Crítica en Situación de Emergencia, publicada por el Consejo de Salubridad General de México. ${ }^{20}$

\section{Conflicto de intereses}

Los autores declaran no tener conflictos de intereses.

\section{Financiamiento}

Los autores no recibieron patrocinio para elaborar este artículo.

\section{Responsabilidades éticas}

Protección de personas y animales. Los autores declaran que para esta investigación no realizaron experimentos en seres humanos ni en animales.

Confidencialidad de los datos. Los autores declaran que en este artículo no aparecen datos de pacientes.

Derecho a la privacidad y consentimiento informado. Los autores declaran que en este artículo no aparecen datos de pacientes.

\section{Bibliografía}

1. World Health Organization [sitio web]. Suiza: Report of the WHO-China joint mission on coronavirus disease 2019 (COVID19); 2020.

2. World Health Organization [sitio web]. Suiza: Global surveillance for human infection with novel coronavirus (2019-nCoV): interim guidance; 2020.

3. Wenzhong Liu, Hualan Li. COVID-19: Attacks the 1-beta chain of hemoglobin and captures the porphyrin to inhibit human heme metabolism. ChemRxiv. 2020 Jul 13; preprint.

4. Secretaría de Salud [sitio web]. México: Lineamiento estandarizado para la vigilancia epidemiológica y por laboratorio de COVID19; 2020.

5. Secretaría de Salud [sitio web]. México: Datos epidemiológicos; 2020.

6. Ministerio de Sanidad. Manejo clínico de pacientes con enfermedad por el nuevo coronavirus (COVID-19). España: Ministerio de Sanidad; 2020.

7. Chen H, Guo J, Wang C, Luo F, Yu X, Zhang W, et al. Clinical characteristics and intrauterine vertical transmission potential of COVID-19 infection in nine pregnant women: a retrospective review of medical records. Lancet. 2020;395(10226):809-815.

8. Centers for Disease Control and Prevention. Interim infection prevention and control recommendations for patients with confirmed 2019 novel coronavirus (2019-nCoV) or persons under investigation for 2019-nCoV in healthcare settings. EU. UU; 2020. 
9. Cao B, Wang Y, Wen D, Liu W, Wang J, Fan G, et al. A trial of lopinavir-ritonavir in adults hospitalized with severe Covid-19. N Engl J Med. 2020;7:1787-1799.

10. Kouznetsova V, Huang D, Tsigelny IF. Potential COVID-19 Protease inhibitors: repurposing: repurposing FDA approved drugs. ChemRxiv. 2020.

11. Wang Y, Zhang D, Du G, Du R, Zhao J, Jin Y, et al. Remdesivir in adults with severe COVID-19: a randomised, double-blind, placebo-controlled, multicentre trial. Lancet. 2020;395:1569-1578.

12. Holshue ML, DeBolt C, Lindquist S, Lofy KH, Wiesman J, Bruce H, et al. First case of 2019 novel coronavirus in the United States. N Engl J Med. 2020;382:929-936

13. Ni YN, Chen G, Sun J, Liang BM, Liang ZA. The effect of corticosteroids on mortality of patients with influenza pneumonia: a systematic review and meta-analysis. Crit Care. 2019;23:99.

14. Caly L, Druce JD, Catton MG, Jans DA, Wagstaff KM. The FDA-approved drug ivermectin inhibits the replication of SARS-CoV-2 in vitro. Antivira Res. 2020;178:104787.
15. Smit MR, Ochomo E, Aliayyoussi G, Kwambai T, Abong'o B, Bayoh N Efficacy and safety of high-dose ivermectin for reducing Malaria transmission (IVERMAL): protocol for a double-blind, randomized, placebo-controlled, dose-finding trial in Western Kenya. JMIR Res Protoc. 2016;17:e213.

16. Huang $C$, Wang $Y$, Li X, Ren L, Zhao J, Hu Y, et al. Clinical features of patients infected with 2019 novel coronavirus in Wuhan, China. Lancet. 2020;395:497-506.

17. Sanders JM, Monogue ML, Jodlowski TZ, Cutrell JB. Pharmacologic treatments for coronavirus disease 2019 (COVID-19): a review. JAMA 2020;323:1824-1836.

18. Guan WJ, Ni ZY, Hu Y, Liang WH, Ou CQ, He JX, et al. Clinical characteristics of coronavirus disease 2019 in China. N Engl J Med. 2020;382:1708-1720.

19. Shiraki K, Daikoku T. Favipiravir, an anti-influenza drug against life-threatening RNA virus infections. Pharmacol Ther. 2020;107512.

20. Consejo de Salubridad General. Guía Bioética para Asignación de Recursos Limitados de Medicina Crítica en Situación de Emergencia. México: Consejo de Salubridad General; 2020. 